\title{
New clinical and toxicological scenario of gammaglutamyltranspeptidase
}

\author{
Ramón Bataller-Sifre ${ }^{1}$, Victoria Guiral-Olivan² and Luis Bataller-Alberola ${ }^{3}$ \\ ${ }^{1}$ Professor Emeritus at the Valencian Community. ${ }^{2}$ Department of Internal Medicine. Hospital Clinico Universitario. \\ Valencia, Spain. ${ }^{3}$ Department of Neurology. Hospital Universitario La Fe. Valencia, Spain
}

\begin{abstract}
After the discovery of gammaglutamyltranspeptidase in 1950 by Hanes, the significance of its increased levels in clinical practice has mainly been focused on ethanol toxicity, and also some neoplasms and biliary tract obstruction.

More recently, attention has swift to the metabolic functions of this enzyme, as a neutralizer of oxygen free radicals and as a glutathione donor to the cell. High serum levels of gamma-glutamyltranspeptidase is known to occur when oxidative stress is increased, or associated with several vascular risk factors and the insulin resistance syndrome, as an early marker of diabetes.

There are also a number of drugs that induce the expression of the tissue enzyme (microsomes) with the result of high serum levels without structural damage to the liver.

Because it is a ubiquitous enzyme, a very high number of causes can be involved, that may be difficult to recognize.

Finally, because glutathione is necessary to conjugate a number of chemical compounds, from an epidemiological and toxicological perspective, the enzyme might be useful as a biomarker of several ambient toxins.

In this review we want to emphasize the increasing clinical and diagnostic significance of this enzyme discovered half a century ago.
\end{abstract}

Key words: Gammaglutamyltranspeptidase. Glutathione. Oxidative stress. Enzyme induction. Chronic hepatopathies. Diabetes mellitus. Environmental toxins. Cardiovascular risk.

Bataller-Sifre R, Guiral-Olivan V, Bataller-Alberola L. New clinical and toxicological scenario of gammaglutamyltranspeptidase. Rev Esp Enferm Dig 2011; 103: 586-590.

Acknowledgements: We thank Dr. Ramón Bataller Alberola for his supervision and for providing the bibliography and $\mathrm{M}^{\mathrm{a}}{ }^{\mathrm{a}}$ Dolores Alberola García for the technical correction of the text.

Received: 11-01-11.

Accepted: 11-01-11.

Correspondence: Ramón Bataller Sifre. c/ Gran Vía Marqués del Turia 52. 46005 Valencia.

e-mail: ramon.bataller@uv.es

\section{INTRODUCTION}

Gammaglutamyl transpeptidase (GGT) is an enzyme that belongs to the family of transferases (1); catalyzes the transfer of a gamma-glutamyl group, of a gamma-glutamyl peptide (such as glutathione: GSH) to a peptide or amino acid-type acceptor (2).

It was discovered in 1950 by Hanes (3), but it took several years to enter the clinical background $(1,4,5)$, therefore it is currently determined within the poorly named hepatic "tests" (GOT, GPT, FA and others).

To a certain degree elevations of serum GGT have been associated with alcohol intake (6), reducing its value in many more clinical processes, although it is true that some of them are quite infrequent (Table I), and at times its etiology remains unclear, which prompted us to undertake this review.

Finally, the role assigned to it more recently as a risk factor for acute myocardial infarction (AMI) and stroke $(7,8)$, and in certain degree as precursor of the onset of type II diabetes (9), adds interest to an overhaul of the mechanisms and significance of the alterations of this enzyme.

\section{ANATOMO-CYTOLOGICAL LOCALIZATION OF GGT}

The largest supply, by far, is in the kidney (10-13) where it is found in tubular cells, from where it passes to urine; by taking the kidney as a reference for GGT content (100 units), absolute figures show that the concentration in the pancreas is 8.3,3.9 in the liver and 1.5 in the spleen (12). It is also found in other organs; intestine $(1,13)$, prostate (13), synovial membrane (14), lung (15), brain (15), lactating breast (15); in large amounts in the endothelial cells of capillaries (16) and in muscles (18). Its preferential localization is epithelial cells, which are in charge of transport (18). It is known that GGT is not found in erythrocytes (18).

Regarding its location in the hepatobiliary system (from which most clinical implications relating to this enzyme 
Table I. Elevated serum GGT in processes not primarily hepato-biliary-pancreatic

- Drugs (propafenone, phenytoin, phenobarbital, warfarin) $(13,20,34,40)$

- Toxics (pesticides, lead, arsenic) (3)

- Angina de pectoris, IAM $(13,15,17,20,39)$

- Diabetes $(13,15,17,20)$

- Obesity, hyperlipidemia $(13,15,39)$

- Congestive heart failure (13)

- Nephropathies (neoplasias, renal infarction, nephrotic syndrome, renal insufficiency) $(15,17)$

- $\operatorname{COPD}(2,15,17,39)$

- CNS $(13,15)$ and neuroperipheral disorders (Guillain-Barré) (13)

- Myopathies (myotonic dystrophy) (13)

- Dementias, nervous anorexia, depression $(13,39)$

- Hyperthyroidism (13)

- Arthropathies (brucellosis, tuberculosis, RA) $(14,15)$

- Neoplasms, radiotherapy (13)

- Porphyria cutanea tarda (13)

- Post-surgery condition (15)

derive), it is predominantly found in the biliary pole of the biliary conducts' cell and epithelium $(2,10,18)$. However, it is also found in the hepatocyte, in both the cytosol (19) and the smooth endoplasmic reticulum (ER) (where it is susceptible to induction, e.g., through drugs) (20), as well as in mitochondria (21) in the following respective percentages: 15,75 and 15 .

\section{FUNCTION}

GGT is engaged in the synthesis of peptides and proteins, in the regulation of the GSH levels in tissues, and in the transport of amino acids through cell membranes $(16,22)$; the natural substrate of GGT is glutathione (23), whose hydrolysis catalyzes and forms part of the general activation and metabolization context of several compounds (and of some drugs in particular); when this enzyme increases in the liver, it can condition the appearance of hepatocellular necrosis $(23,24)$.

The so-called oxidative stress (OS) originates (25) when an imbalance of pre-oxidation versus anti-oxidation takes place to favor the former; e.g., when oxygen-free radicals (OFR) are generated because of different deleterious causes (Fig. 1). These OFR react with other molecules by converting them into reactive oxygen species (ROS) (26) which, in turn, can bring about different effects (modulation of cytokines' expressions, auto-antigens production (5), modification of biomolecules -DNA, proteins, lipids- and formation of toxic species such as lipid peroxides) (27).

GSH acts as an antioxidant (25) as it neutralizes the OFR thanks to the sulfur hydride of the cysteine that enters its tripeptide composition (gamma-glutamyl-cysteine-glycine); as it is contained in erythrocytes, it protects them from membrane oxidation (28). GSH can be oxidized $v s$. reduced by constituting the redox system. GGT provides cells with GSH from serum (17) by acting as an intracellular antioxidant (29). The level of GGT indicates increased OS (30), and has been associated with various cardiovascular risk factors and with insulin resistance syndrome components. Thus, it would be an early biomarker for the development of diabetes. Oxidative stress (OS) is a component of several reactions associated with chronic inflammation; $\mathrm{C}$-reactive protein (c-RP) is a marker of chronic inflammation and GGT has been positively associated with c-RP concentrations (30). Indeed, the correlation between c-RP and GGT will help elucidate the association between OS and inflammation. GGT also modulates the activity of several inflammatory mediators such as leukotrienes, nitric oxide and interleukins (31).

GGT levels are very high in neonates and in children under the age of one, and increase after the age of 60 (13); $6 \%$ of men present abnormal values.

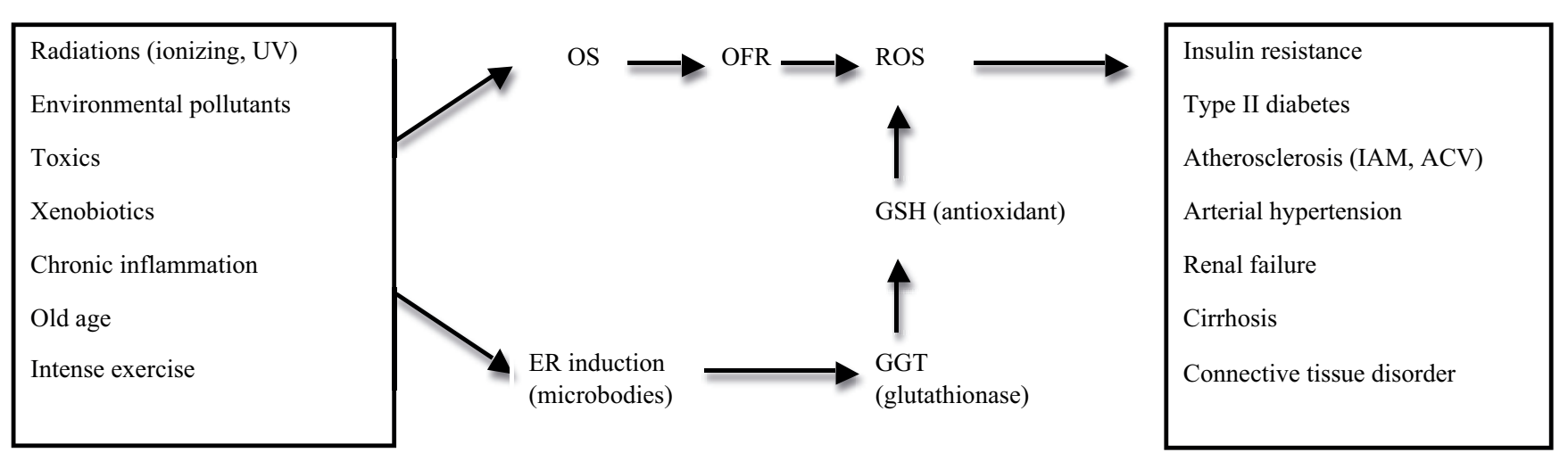

Fig. 1. Metabolic pathophysiological hypothesis of GGT. 


\section{DIAGNOSTIC VALUE}

A question that still remains unknown is the reason why GGT does not increase in renal diseases (with the exception of nephrotic syndrome and acute tubular cell injury), being by far the organ with highest content of said enzyme (11).

An increased serum GGT in the general analytical examination, evokes in the clinician abuse of ethanol, often associated with hepatic dysfunction, altered synchronous "markers" that would confirm said toxic origin (6), such as increase of MCV in red blood cells, of uric acid and triglycerides, as well as potassium and magnesium decrease. Isolated increase of GGT would have a low sensitivity and specificity to detect alcohol abuse (32). When GGT increase is isolated (without increase of GOT or other hepatic parameters) the biopsy does not reveal inflammatory signs or irreversible histopathological changes, whereas if it is associated with increased GOT and other hepatic indicators substantial inflammatory changes are observed.

Overall, there is a correlation between GGT tissue content, histochemically evaluated (33), and enzyme serum levels in different hepatopathies, although with wide oscillation, particularly in alcoholic hepatopathies, but not in non-alcoholic cirrhosis and severe cholestasis, in these latter due to the tissular "washed-out-effect" caused by the local increase of bile acids.

Numerous drugs induce tissue GGT (microsomes) that may result in increased serum levels that do not entail structural damage (35); such as certain antiarrhythmics (propafenone, disopyramide) (34), phenytoin, phenobarbital and warfarin (20), among others.

In $52 \%$ of low-activity chronic hepatitis $(\mathrm{CH})$ (formerly called "persistent") its GGT increase is usually associated to that of GOT (34); in any of the cases of this type with normal values of GOT or GPT, GGT is increased. Conversely, in $41 \%$ there is an increase of GOT with normal GGT. In chronic active-type hepatitis the behavior of the three enzymes is less homogeneous: one third present with GOT vs. normal GGT and 10\% with normal GPT and increased GGT. Everything suggests that this lack of homogeneity is because GGT is raised not only by cytolysis and/or increase of permeability -as it is the case of GOTGPT- but also due to certain enzyme induction at the level of the ER of complex cause, not only external.

The diagnostic value of the increases of GGT should be usually associated, among other data, with the levels of GOT-GPT, having no diagnostic advantage over the latter, despite its greater sensitivity (15).

High figures of GGT have been associated with a higher risk of hepatocarcinoma (36), by generating pro-oxidant active metabolites, resulting in an imbalance of cell proliferation/death processes, GGT isoenzymes are useful in the diagnosis of hepatoma, especially in those where alphafetoprotein is normal (37); $51 \%$ of hepatomas are located in fraction I, attributing to the I a high specificity.

An issue discussed a few years ago was the late increase of GGT in IAM (in 50-70\% of the cases) (13), on day 5 approximately, returning to normal levels on day 30 (38). In principle, this was not attributable to cytolysis (given the scarce amount of GGT contained in the heart), but rather to the passive congestion of the liver with hepatocellular anoxia, although more probably by association to capillary revascularization that originates in the necrotic area, and given the large amount of GGT contained in capillary endothelial cells (16).

In addition, it can be raised in congestive cardiac insufficiency $(13,15)$, angina pectoris $(13,15)$, chronic obstructive pulmonary disease (COPD) $(2,15,39)$, post-surgery status $(15)$, diabetes $(13,15)$, obesity and hyperlipidemia $(13,15,39)$, hypertiroidism (13), certain nephropathies (neoplasias, renal infarction, nephritic syndrome) (15), drugs $(13,20,34,40)$ and toxics (ethanol, pesticides, lead, arsenic) $(3,13,17,41)$, CNS $(13,15)$ y and neuroperipheral diseases (Guillain Barré syndrome) or muscular (myotonic dystrophy) (13), mental disorders (dementias, depression, anorexia nervosa) $(13,39)$, radiotherapy $(13,39)$ and porphyria cutanea tarda (13).

The presence of GGT in synoviocytes explains its rise in synovial fluid, particularly in brucellosis, tuberculosis and rheumatoid arthritis (RA) in exacerbation phase $(14,15)$, while remaining at low levels in arthritis, gouty arthritis and RA in chronic phase.

In table I we present the causes of elevated serum GGT in patients without prior hepato-biliary-pancreatic processes.

It is worth mentioning cocaine, which cannot be attributed as a cause of liver disease (and of other structures), as it occurs with the other addictions to drugs of abuse and given the extent of its consumption in western countries, especially in Spain, as a possible cause for GGT elevation not yet clarified. It has been postulated (42) that a mechanism of its toxic action would be mediated by lipid peroxidation caused by ROS; since GGT is an early marker of subclinical hepatic steatosis (43) and this histopathological change is described among those caused by cocaine (44) it is necessary to increase knowledge on the hepatotoxicity of said substance.

\section{PROGNOSTIC AND TOXICOLOGICAL ASPECTS}

Increased GGT is considered a risk factor for AMI and CVA $(7,8)$; GGT has been found to be catalytically active in atherosclerotic platelets, and a linear correlation exists between total GGT in serum and the activity corresponding to beta-lipoproteins, which partially absorb circulating GGT.

GGT levels are also positively associated with the incidence of diabetes mellitus (9), and more significantly so with nondrinkers than with drinkers. Obesity would not be a determining factor for diabetes to emerge if GGT levels are low (9).

As mentioned earlier, one relevant aspect is an increase in GGT due to the action of some environmental chemical toxins; GSH is the biomolecule required for combining different chemical substances (45). Thus, the longer the expo- 
sure to these products, the higher the number of GSH combinations, and cellular GGT is necessary for their subsequent metabolism; thus, GGT would be a biomarker of several chemical environmental substances. This proves a fascinating field to advance into the expansion required for toxicology in clinical and preventive medicine.

\section{REFERENCES}

1. Rodríguez-Cuartero A, Núñez-Carril J, Mora-Lara RJ, Peláez-Redondo J. Gamma-glutamil-transpeptidasa en cardiopatías coronarias. Rev Clín Esp 1973;132:21-8.

2. Wilkinson JH. The Principles and Practice of Diagnostic Enzymology. Londres: Arnold; 1976: p. 85-87, 345.

3. Hanes CS, Hird F, Isherwood FA. Synthesis of peptides in enzymatic reactions involving glutathione. Nature (Londres) 1950;166:288-92.

4. Van der Reis L. Enzymology of the Liver. Basilea: Karger; 1976.

5. Paumgartner G, Preisig R. The Liver. Quantitative Aspects of Structure and Function. Basilea: Karger; 1973.

6. Ferenci P. Clinical spectrum of alcoholic steatohepatitis. En: Leuschner U, James OFW, Dancygler H, editors. Dordrecht: Kluwer; 2000. p. 240.

7. Paulichi A, Emdin M, Passino C, Lorenzini E, Titta F, Marchi S, et al. Beta-lipoprotein and LDL-associated serum gammaglutamyl-transferase in patients with coronary atherosclerosis. Atherosclerosis 2006;186:805 .

8. Shimizu Y, Imano H, Ohira T, Kitamura A, Kiyama M, Okada T, et al. Gammaglutamyltranspeptidase and incident stroke among Japanese men and women: the circulatory risk in communities study. Stroke 2010;41: 385-588.

9. Fujita M, Veno K, Mata A. Association of gammaglutamyltransferase with incident of type 2 diabetes in Japan. Exp Biol Mol 2000;235:33541.

10. Gibinski K. La gamma-glutamyl-transpeptidase a l' etat physiologique et pathologique. Rev Int D' Hepatologie 1966;16:1249-68.

11. Renner EL. Liver Function Test. In: Hayes PC, editor. Investigations in Hepatology. Londres: Bailliere Tindall; 1995. p. 664.

12. Szczerklik E, Orloowski M, Szewczuc A. Serum gammaglutamyl activity in liver diseases. Gastroenterology 1961;41:353-8.

13. Mc Intyre N, Rosalki S. Biochemical investigations in the management of liver disease. In: Prieto J, Rodés J, Shafritz DA, editors. Hepatobiliary diseases. Berlín: Springer; 1992. p. 51-3.

14. González Buitrago JM, González Muñoz MA, Alcalá Santaella R, Navajo JA. Gammaglutamiltransferasa en líquido sinovial en diversos procesos articulares. Rev Esp Reumatol 1983;10:48-50.

15. Hardison WGM. Gammaglutamyltranspeptidase: A Clinical Ovewiew. In: Griffitns JC, editor. Clinical Enzymology. Nueva York: Masson SA; 1979. p. 199-206.

16. Rodriguez Cuartero A. Comportamiento de la gammaglutamil-transpeptidasa en el infarto de miocardio. Med Clín (Barcelona) 1973;61: 257-9.

17. Stolz AS, Kaplowitz N. Biochemical Test for Liver Disease. In: Zakim D, Boyer ThD. Philadelphia: Saunders; 1990. p. 658-9.

18. Laperche Y. La gammaglutamiltranspeptidase hépatique. Gastroenterol Clin Biol 1989;13:783-90.

19. Ivanov E, Krustev L, Adjarov L,Chernev K, Apostolov L, Dimitrov P et al. Studies on the mechanism of the changes in serum and liver gammaglutamiltranspeptidase activity. Enzyme 1976:21:8-20.

20. Wise BL, Luckayne S. Enzymes, In: Bishop ML, Duben-Von Laufen, Fody E, editors. Clinical Chemistry. Londres: Lipincott; 1985: p. 205-39.
21. Fusijama K, Takahashi T. Serum gammaglutamyltranspeptidase and chronic liver injury. $4^{\circ}$ Meeting IASL. Elsinor; 1970.

22. Rosalki SB. Gammaglutamyltranspeptidase. Adv Clin Chem 1975; 17 53-107.

23. Shaw LM. Molecular properties of gammaglutamyltransferase. In: Delmers LM, Shaw LM, editors. Evaluation of Liver Function. Baltimore-Munich: Urban \& Schwarzenberg; 1978. p. 103-21.

24. Ameer B, Greenblatt DJ. Acetaminophen. Ann Intern Med 1977;87: 202-9.

25. Elejalde-Guerra JI. Oxidación, entre la vida y la enfermedad. Ann Med Int (Madrid) 2001;18:1-4.

26. De la Peña-Fernández A, Redondo Bellón P. Radicales libres y mecanismos antioxidantes. Generalidades y aplicaciones en la práctica clínica. Rev Clín Esp 1997;197:434-56.

27. Medina J, Sanz-Cameno P, Matín-Vilchez S, Moreno-Otero R. Pathophysiological basis for antioxidant therapy in chronic liver diseases. In: Moreno-Otero R, Albillos A, Bañares R, Cuevas-Mons V, Medina J, editors. Immunology and the Liver: immunotherapy. Madrid: 2004. p. 47-60.

28. Reuter P. Springer Lexikon Medizin. Berna: 2004. p. 825.

29. Lee DH, Ha MH, Kim JH. Gammaglutamyltransferase and diabetes. A 4 year follow-up study. Diabetología 2003;46:359-64.

30. Lee DH, Jacobs DR Jr. Association between serum gammaglutamyltransferase and C-reactive protein. Atherosclerosis 2005;178:327-30.

31. Paolichi A, Marchi S, Petrucelli, Ciancia C, Malvaldi G, Pompella A Gammaglutamyltransferase in fine needle liver biopsies of subjects with chronic hepatitis C. J Viral Hepat 2005;12:269-73.

32. Ireland A, Hartley L, Ryley N, O’ D Mc Gee J, Trowell JM, Chapman RW. Raised gammaglutamyltransferase activity and the need for liver biopsy. Br Med J 1991;302:388-9.

33. Busachi C, Mebis J, Broeckaert L, Desmet V. Histochemistry of gammaglutamyltranspeptidase in human liver biopsies. Path Res Pract 1981;172:99-108.

34. Balcells A, Costa J, Cano JF, Ballesta A. Gammaglutamiltranspeptidasa en hepatitis crónicas. Su interés clínico. Med Clin (Barcelona) 1976; 66:429-30.

35. Bataller Sifre R, Rosique Martínez A. Valor recíproco de la gammaglutamiltranspeptidasa, fosfatasa alcalina y bilirrubina total en hepatopatías crónicas difusas. Rev Esp Enferm Dig 1979;56:327-41.

36. Hua-Yun S, Sai-Fang GT, Sai-Fang S. Assessment of diagnosis value of gamma-GT isoenzyme for hepatocellular carcinoma. Chinese J Intern Med 1986;25:341-3.

37. Kojima J, Kanatawi M, Naikamura T, Kashimag T, Tohjo G, Akiyama M. Electhrophoretic fractionation of serum gammaglutamyltranspeptidase in human hepatic cancer. Clin Chim Acta1980;106:165-72.

38. De Castro del Pozo S, Pérez- Sandoval D, Moreno de Vega V, Bondía M. Actividad de la gammaglutamiltranspeptidasa en el infarto de miocardio. Rev Clin Esp 1973;128:317-22.

39. Dechelette P. Valeur diagnostic et pronostique de la GGT dans les maladies hepatiques. (tesis doctoral). Universidad de Lyon; 1974.

40. Kumar V, Cotran R, Robbins SL. Basic pathology. Philadelphia: Saunders; 1992.

41. Kashyap SK. Health surveillance and biological monitoring of pesticide formulators in India. Toxicol Lett 1986;33:107-14.

42. Albertson TE, Chan A, Tharrat RS. Cocaine. En: Shaunon MW, Borron SW, Burns MJ, editors. Clinical management of poisoning and drug overdose. Philadelphia: Saunders; 2007. p. 755-72.

43. Lee DH, Jacob Jr DR. Serum gammaglutamyltransferase: new insights about an old enzyme. J Epidemiol Community Health 2009;63:884-6.

44. Mac Sween RNM, Burt AD, Portmann BC, Gishak K, Scheuer PJ, Anthony PP. Pathology of the liver. Londres: Churchill Livingstone; 2002. p. 96

45. Tate SS, Meister A. Gammaglutamyltranspeptidase: catalytic, structural and functional aspects. Mol Cell Biol 1981;39:357-68. 